\title{
MONITORIA DE QUIIMICA: AULAS DE REFORÇO COMO ESTRATÉGIA PARA FACILITAR A APRENDIZAGEM
}

ACADEMIC MONITORING CHEMISTRY: TUTORING AS A STRATEGY TO FACILITATE

LEARNING

Elaine Santos Silva ${ }^{1}$, Emilly Adorno de Lima Vasconcelos², Maria de Fatima Mendes Paixão

DOI: $10.37702 / R E E 2236-0158 . v 39 p 420-431.2020$

\section{RESUMO}

O presente trabalho teve como objetivo avaliar a contribuição dada pela monitoria acadêmica da disciplina Química Geral e Inorgânica I como atividade facilitadora da aprendizagem. O componente curricular citado pertence ao primeiro semestre do curso de graduação em Engenharia de Alimentos da Universidade Estadual de Feira de Santana (UEFS) e seu acompanhamento requer que os estudantes tragam consigo alguns conhecimentos químicos do Ensino Médio para serem aprofundados e servirem como saberes básicos para disciplinas posteriores. Observa-se que os alunos apresentam grande carência nesses conhecimentos, gerando alto índice de repetência e evasão. Para reduzir o impacto causado pelas lacunas no conhecimento, são realizadas aulas de reforço pela monitoria de Química em horário extraclasse, utilizando-se materiais didáticos variados. Para avaliar o potencial de contribuição dado por essa atividade, foi elaborado um questionário com perguntas abertas e fechadas e aplicado aos estudantes que cursaram a disciplina no primeiro semestre de 2018. As informações obtidas foram organizadas em gráficos e analisadas à luz da literatura científica disponível. Os resultados mostraram que as contribuições das aulas de reforço cumpriram seu papel, funcionando como uma atividade capaz de intermediar a aquisição de conhecimentos pelos estudantes monitorados, de promover seu engajamento com a comunidade universitária, bem como de aproximálos de seu objeto de estudo.

Palavras-chave: Ensino de Química; evasão e retenção; monitoria.

\begin{abstract}
The purpose of this work was to evaluate the contribution made by the academic monitoring of the discipline Química Geral e Inorgânica I as an activity that facilitates learning. The mentioned discipline belongs to the first semester of the undergraduate course in Food Engineering at the State University of Feira de Santana (UEFS). It requires that the students bring with them some high school chemical knowledge which must be deepened to be used in later disciplines. However, it is observed that students have a great gap of this knowledge generating a high rate of repetition and dropout. In order to reduce the impact caused by it reinforcement classes are carried out by academic monitoring chemistry in extra-class time, using many teaching materials. In order to know the contribution gave by this activity, a questionnaire was prepared with open and closed questions and applied with some students. The information obtained with them was organized and the date were analyzed using the available scientific literature. The results showed that the monitoring contributions via tutoring classes fulfilled their role, functioning as an activity capable of intermediating the acquisition of knowledge by the monitored students, promoting their engagement with the university community, as well as bringing them closer to their object of study.
\end{abstract}

Keywords: Chemistry Teaching; evasion and retention; academic monitoring.

\footnotetext{
${ }^{1}$ Graduanda em Engenharia de Alimentos, Universidade Estadual de Feira de Santana; santoselaine95@gmail.com

${ }^{2}$ Graduanda em Engenharia de Alimentos, Universidade Estadual de Feira de Santana; millyadorno95@gmail.com

${ }^{3}$ Profa. Dra. do Departamento de Ciências Exatas da Universidade Estadual de Feira de Santana; fpaixao100@gmail.com
} 


\section{INTRODUÇÃO}

Os componentes curriculares do ciclo básico de cursos de graduação da área das Ciências Exatas - como as Engenharias - são oferecidos geralmente nos quatro primeiros semestres de curso e têm como objetivo fornecer embasamento para as disciplinas posteriores. Observa-se, de maneira geral, que o primeiro ano é quando há o maior índice de evasão e de retenção nas disciplinas básicas dos cursos universitários mencionados (OLIVEIRA; PASSOS, 2014).

Química Geral e Inorgânica I é o componente curricular introdutório dessa Ciência para o curso de Engenharia de Alimentos e de Farmácia na Universidade Estadual de Feira de Santana (UEFS), pertencente à grade curricular como disciplina do primeiro semestre. Através dela, alguns conceitos básicos são apresentados aos estudantes, enquanto outros são repassados, pois já fazem parte do currículo do Ensino Médio, devendo apenas ser aprofundados e abordados com uma linguagem apropriada ao Ensino Superior.

Entretanto, são observadas lacunas nesse conhecimento que foram deixadas pelo ensino básico; não só no que diz respeito aos conteúdos de Química, mas também em saberes de outras Ciências (como Matemática ou Física) ou na leitura e interpretação de textos, que se transformam em fatores que geram um alto índice de repetência e de abandono do componente curricular supracitado, criando uma grande demanda de alunos que necessitam cursar novamente Química Geral e Inorgânica I em semestres posteriores ao primeiro.

Nesse contexto, visando a buscar soluções que contribuam com a aprendizagem dos estudantes e a suprir as carências nos saberes dos estudantes, participamos, desde 2007, dos editais do Programa de Bolsa Monitoria (PBM) oferecidos pela Pró-Reitoria de Graduação (PROGRAD /UEFS), através do projeto intitulado Monitoria de Química Geral e Inorgânica I. Após seleção, o monitor aprovado deve realizar o plano de trabalho proposto pelo projeto. Neste estão descritas as funções a serem desenvolvidas durante o ano, as quais incluem acompanhamento da disciplina e colaborando com o professor orientador em suas ações docentes. Além disso, o projeto orienta o monitor a realizar iniciação à pesquisa, via de regra, na área de Educação, como forma de estimulá-lo à leitura e à escrita de textos científicos.

A consolidação da ideia de pesquisa em Universidades ocorreu no século XIX, na Europa, quando à atividade de ensino associouse a de geração de conhecimento, ou seja, coexistiam geração e transmissão. No Brasil, a implantação dessa ideia foi lenta, demorando a disseminar-se pelo país, até que pudéssemos chegar ao que temos atualmente em termos de pesquisa (BARRETO; FILGUEIRAS, 2007).

Assim, a academia vai deixando de ser apenas um centro transmissor de conhecimentos para ser também centro gerador e propagador dos saberes produzidos. Hoje, a Universidade "se sustenta em três pilares ensino, pesquisa e extensão - que cada vez mais necessitam estar inter-relacionados" (ALBUQUERQUE et. al, 2012, p. 139).

No Brasil, a monitoria foi instituída nas Universidades pela Lei n. 5.540/68, que estabeleceu em seu artigo 41 que:

\section{As universidades deverão criar as funções de monitor para alunos do curso de graduação que se submeterem a provas especificas, nas quais demonstrem capacidade de desempenho em atividades técnico-didáticas de determinada disciplina. \\ Parágrafo único. As funções de monitor deverão ser remuneradas e consideradas título para posterior ingresso em carreira de magistério superior (BRASIL, 1968, n.p.).}

Posteriormente, em 1970, o Decreto 66315, que dispunha sobre a participação do estudante em trabalhos relacionados ao magistério, descreveu detalhadamente as funções do monitor. O estudante, para pleitear monitoria, deve ter desempenho comprovadamente satisfatório na disciplina objeto dessa monitoria e auxiliar os docentes do ensino superior em suas atividades técnicopedagógicas. As Universidades estabeleceriam as normas para seleção, as disciplinas e o perfil do estudante candidato, com regime de trabalho 
de $12 \mathrm{~h}$ por semana, sob a orientação de um docente (DIAS, 2007).

De acordo com Lins et al. (2009, n.p.), a atividade de monitoria pode ser definida como uma "modalidade de ensino e aprendizagem que contribui para formação integrada do aluno nas atividades de ensino, pesquisa e extensão", um instrumento para melhoria do ensino de graduação, capaz de "promover a cooperação mútua entre discente e docente e a vivência com o professor e com as suas atividades técnicodidáticas".

Outra definição para monitoria, dada pelo Guia do Monitor e do Professor Orientador da UEFS, citado por Amorim, Paixão e Silva (2017), informa que se trata de um tipo de iniciação à docência oferecida aos alunos graduandos da UEFS, com o objetivo de contribuir para sua formação acadêmicoprofissional em determinada área do conhecimento.

A monitoria acadêmica na UEFS é gerenciada pela PROGRAD e normatizada pela Resolução CONSEPE 40/2001; atualmente tem-se também as Resoluções CONSEPE 208/2010; 81/2011 e 093/2017 que normatizam o PBM/UEFS (AMORIM; PAIXÃO; SILVA, 2017).

Devido à necessidade de aumentar o número de monitores e a fim de dar uma orientação mais individualizada ao alunado de Química Geral e Inorgânica I, desde 2009, quando a UEFS ainda não possuía seu Programa de Monitoria Voluntaria, iniciou-se um trabalho com esse formato (monitores voluntários). $\mathrm{Na}$ época, oferecíamos como contrapartida apenas o aprofundamento no conhecimento em Química e a possibilidade de contar as horas de trabalho como carga horária complementar para seu curso de graduação.

No segundo semestre de 2016, a PROGRAD normatizou a Monitoria Voluntaria, através da Resolução Normativa 02/2016, inserindo o Programa de Monitoria Voluntaria no âmbito do PBM /UEFS, destinado a estudantes que se interessem por essa atividade. Apesar de os monitores voluntários não contarem com o auxílio financeiro, recebem da PROGRAD um certificado de participação e podem inserir essa experiência em seu Currículo Vitae. Associada a isso, a inserção de um aluno no processo de monitoria possibilita a este estudante melhorias em seus saberes científicos, favorece a aprendizagem de novas práticas docentes e a aquisição de experiências pedagógicas, fatores que contribuem para sua formação. $\mathrm{Ou}$, ainda, pode auxiliá-lo na escolha do caminho a seguir durante sua graduação.

O PBM faz seleção anual, via edital, para monitores bolsistas. Os monitores voluntários são inscritos semestralmente, mas todos devem cumprir um plano de trabalho individual, associado ao projeto de monitoria. A vantagem de termos a modalidade voluntária se deve também ao fato de se tornar possível ter mais de um graduando colaborador.

As ações de monitoria se realizam a partir do envolvimento de três atores: o professor (orientador), o aluno (monitorado) e o graduando (monitor). O professor é a pessoa capacitada para orientar e supervisionar as atividades exercidas pelos monitores (SILVEIRA; SALES, 2016). Os graduandos monitores auxiliam os docentes no desempenho de suas atividades. No caso de Química Geral e Inorgânica I, o monitor bolsista é o responsável pelas aulas de reforço, atividade que sempre faz parte de seu plano de trabalho. Além disso, devido a sua maior carga horária semanal, deve participar de pelo menos duas aulas de laboratório e é o responsável por criar e atender ao grupo de WhatsApp e ao do e-mail, organizados para facilitar a comunicação entre monitores e seu público-alvo, os alunos monitorados.

Entre as tarefas desempenhadas pelos monitores (bolsistas ou não) podemos citar: preparação de materiais para as aulas (como revisão e atualização de listas de exercícios e roteiros de laboratório); teste de novos experimentos, ou ajustes dos já existentes; orientação dos alunos monitorados na escrita de trabalhos e relatórios ou na realização das pesquisas necessárias para a manipulação de substâncias em laboratório; orientar os estudantes quanto ao uso e manutenção das regras de segurança. $\mathrm{O}$ grupo do WhatsApp e do $e$-mail são usados para esclarecimento de pequenas dúvidas, bem como para passagem de informações acerca da disciplina e para envio de material. As aulas de reforço foram criadas 
para auxiliar os alunos quanto ao esclarecimento de dúvidas relativas aos assuntos do Ensino Médio ou para reforçar conteúdos abordados pelo componente curricular Química Geral e Inorgânica I. Com o passar do tempo, suas ações foram sendo ampliadas e hoje seu foco principal é ser um espaço voltado para discussão de conteúdos e promoção da aprendizagem.

O presente trabalho teve como objetivo avaliar as contribuições dadas pelos monitores para a aprendizagem dos alunos monitorados, dentro do projeto da disciplina Química Geral e Inorgânica I, do curso de Engenharia de Alimentos da Universidade Estadual de Feira de Santana, durante o $1^{\circ}$ semestre de 2018.

\section{METODOLOGIA}

A pesquisa teve caráter exploratório, pois buscou-se obter informações acerca do potencial de aprendizado promovido pelas ações das aulas de reforço ministradas pela monitoria.

A abordagem dada foi mista - qualitativa e quantitativa. Para tal, foi elaborado um questionário com questões abertas e fechadas, aplicado em um grupo de discentes do componente curricular Química Geral e Inorgânica I (UEFS) que cursaram a disciplina durante o primeiro semestre de 2018 e decidiram participar voluntariamente.

Os questionamentos forneceram dados numéricos, que auxiliaram na compreensão e análise das informações coletadas. Para tal, foram organizados gráficos, utilizando o programa EXCEL da Microsoft, que informavam o percentual de cada informação obtida. Essas informações foram analisadas à luz da literatura científica disponível, considerando os aspectos relevantes em cada dado analisado.

\section{RESULTADOS E DISCUSSÃO}

A turma observada era composta por 41 alunos que cursaram a disciplina no primeiro semestre de 2018. Como as aulas de reforço não são obrigatórias, do total, apenas 13 pessoas responderam ao questionário $(30 \%$,$) , pois$ buscou-se conhecer a opinião daqueles que participaram de todas as ações da monitoria, incluindo a não obrigatória.

Geralmente observa-se uma maior frequência nessa atividade na aula anterior à prova, mas, durante o semestre em questão, observou-se boa frequência de determinado grupo durante toda sua duração. Dentro desse grupo estão os 13 alunos participantes da pesquisa.

As aulas de reforço foram criadas por um ex-monitorado, logo após ser aprovado na disciplina. Diante das inúmeras dificuldades por ele sentidas e de seu empenho para buscar auxílio com o monitor bolsista durante o período que cursava a disciplina, após ser aprovado, buscou a coordenadora do projeto de monitoria e propôs ser monitor voluntário e instituir as aulas de reforço. Posteriormente, essas aulas passaram a fazer parte das atividades regulares do plano de trabalho do monitor bolsista e, segundo relatos dos estudantes monitorados, vêm dando importante contribuição para sua aprendizagem.

$\mathrm{O}$ formato original foi se modificando ao longo do tempo, mantendo-se até hoje a participação voluntária. Inicialmente não havia um local específico para os encontros, que aconteciam em uma área de lazer dos estudantes, apenas para esclarecer dúvidas ou para resolver listas de exercícios. Com a observação de sua interferência positiva no andamento da disciplina, após um ano de funcionamento, passou-se a contar a cada semestre com uma sala reservada para tal fim. O departamento de Ciência Exatas, local onde está lotado o projeto de monitoria de Química Geral e Inorgânica I, cede semestralmente uma sala para as aulas de reforço. Outra mudança ocorrida foi a ampliação do número e dos tipos de atividades desenvolvidas.

Aqueles que participaram de todas as ações estavam mais aptos a julgar a influência da monitoria em seu aprendizado, que começa com o ato de ensinar, pois promove o encontro do aluno com o conhecimento em discussão. Nesse sentido, concordamos com Molina (1985) quando afirma que se a preocupação do estudante é apenas revisar para prova - sem haver o questionamento e o debate, visando apenas à devolução de informações em uma 
avaliação para, em seguida, esquecer -, aquela atividade não está contribuindo para formação do sujeito curioso e crítico do mundo em que vive.

Quando o interesse é identificar se as ações estão favorecendo a aprendizagem, então essas ações precisam ser avaliadas por aqueles que a usam para aprender. Assim, perguntamos aos entrevistados como eles percebiam sua frequência nas aulas de reforço: 69\% dos entrevistados disseram que sua frequência foi alta e $31 \%$ que sua frequência foi média, conforme pode ser observado na Figura 1.

O processo atualmente mais utilizado para avaliação da aprendizagem se baseia no uso de instrumentos que visam a atribuir nota $\mathrm{e}$ classificar os alunos, um formato que nem sempre permite a revisão e a reorganização das estratégias de ensino utilizadas. É importante que o professor, ao fazer sua avaliação, esteja seguro de que os instrumentos utilizados são capazes de fornecer informações que vão mais além daquelas oferecidas por uma nota, mas que lhe permita propor e implementar ações capazes de promover a superação das dificuldades de aprendizagem percebidas.

Figura 1 - Percentual de frequência em aulas de monitoria

Qual foi a sua frequência nas aulas de monitoria?

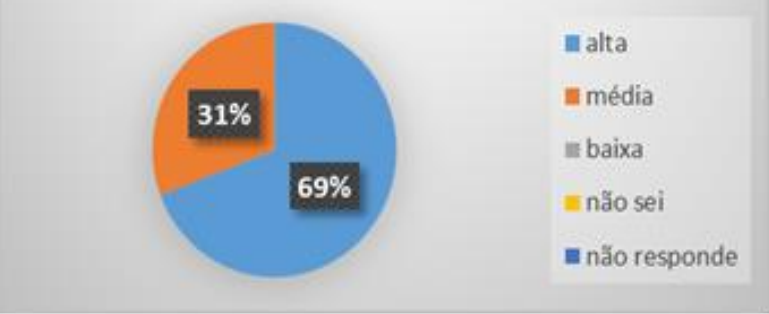

Fonte: elaborada pelas autoras.

As discussões nas aulas de reforço permitiram identificar deficiências apresentadas pelos saberes dos alunos em assuntos básicos de Química e de outros componentes curriculares. Neste sentido, buscou-se ferramentas metodológicas que pudessem auxiliar o desenvolvimento conceitual e promovesse a motivação para aprender. Entretanto, é o compromisso do aluno que permite que os objetivos de ensino sejam alcançados, sendo importante que cada um saiba identificar suas necessidades e queira aceitar os desafios.

Buscou-se conhecer como os estudantes percebiam seu aprendizado em Química no Ensino Médio. A partir das informações do questionário, observou-se que $16 \%$ reconheciam ter construído uma boa base nessa Ciência, $15 \%$ reconheciam que sua base era razoável e $69 \%$ reconheceram como ruim, conforme mostra a Figura 2.

Figura 2 - Conhecimento prévio em Química

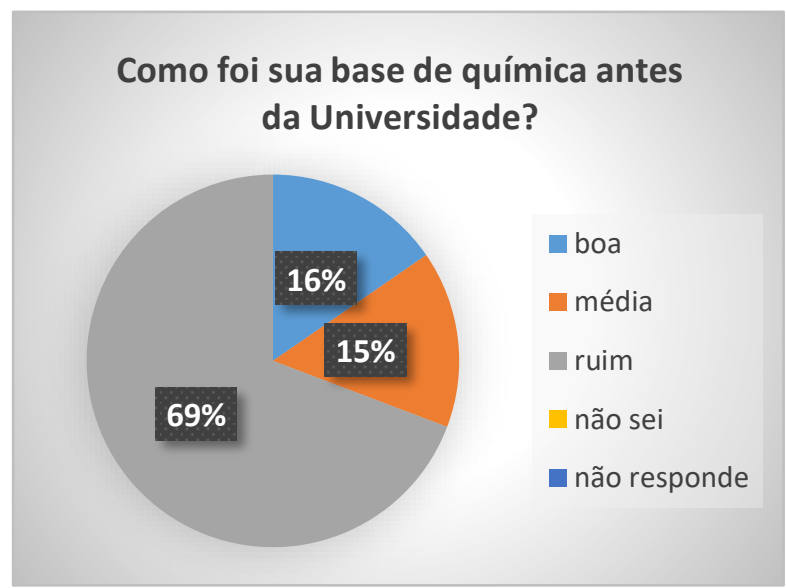

Fonte: elaborada pelas autoras.

As aulas tradicionais não conseguem despertar em todos os alunos o mesmo interesse pelo tema trabalhado ou pela Ciência que está sendo discutida. Além disso, não há uma preocupação com o estudante, com sua motivação e interesses e sim com currículos e programas. Os estudantes entendem então que o que precisam é ser aprovados e seguir com a vida. Dentro do formato tradicional da sala de aula é mais difícil promover mudanças, mas se o professor vê a monitoria como um espaço propício para estimular os alunos a desenvolverem uma nova forma de estudar e de aprender, e passa a orientar os monitores para que utilizem nas aulas de monitoria ferramentas didáticas capazes de instigar a participação do aprendiz e de motivá-lo, é possível estabelecer novos vínculos entre os estudantes e seu objeto de estudo (PESSOA; ALVES, 2011).

O conteúdo trazido do Ensino Médio pelos estudantes pode colaborar com a aprendizagem e com a abordagem dada pelo componente curricular Química Geral e Inorgânica I. Nesse 
sentido, buscou-se identificar a percepção dos estudantes sobre a interferência desse conhecimento. Os resultados estão disponibilizados na Figura 3.

Observa-se na Figura 2 que $69 \%$ reconhecem que sua base em Química no Ensino Médio foi ruim, na Figura 3, 77\% acreditam que a ausência dos conteúdos dificultou o seu aprendizado. Entre estes devem estar incluídos uma parte daqueles $15 \%$ (Figura 2) que acreditam que sua base em Química foi razoável. Comparando ainda as Figuras 2 e 3, observa-se, na Figura 3, que $23 \%$ acreditam que os conhecimentos anteriores ajudaram em seu aprendizado; entre estes devem estar incluídos os $16 \%$ que tiveram boa base e parte daqueles que tiveram uma base razoável.

\section{Figura 3 - Influência da carência de conhecimentos} químicos

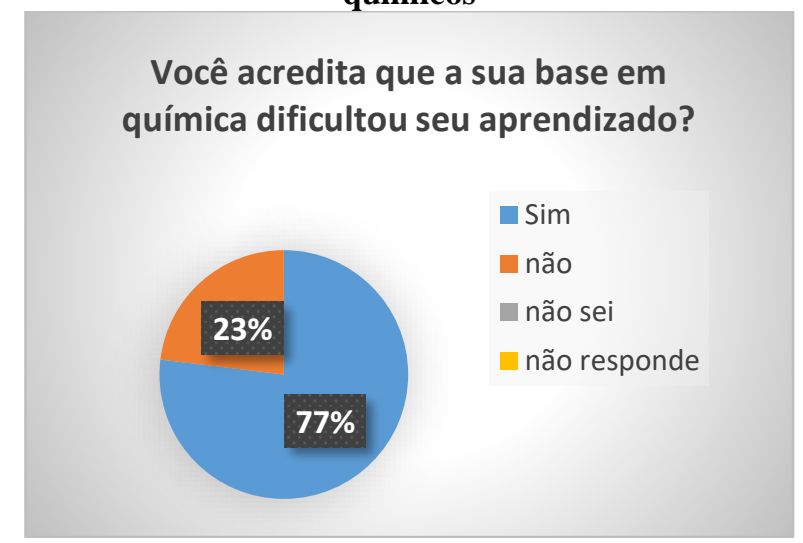

Fonte: elaborada pelas autoras.

$\mathrm{O}$ aprendido pode ser evocado, tanto em situações semelhantes àquelas em que o conhecimento foi gerado quanto em diferentes contextos. "A todo instante nos deparamos com situações novas ou que, mesmo conhecidas, comportam alguns elementos que não estavam presentes ou que se apresentam diferentemente na nova situação" (MARTINELLI; SISTO, 2001, p. 81).

Entretanto, aprender não está ligado apenas ao cognitivo, e cada um tem sua forma de aprender. Existe também uma base afetiva que permeia a relação estabelecida entre alunos, professores, conteúdos e materiais didáticos. Nesse sentido, o professor, ao intervir intencionalmente com vistas a possibilitar a superação de dificuldades, muito comuns e percebidas pelo contínuo exercício da sala de aula, precisa considerar essa afetividade. Quando o estudante conhece suas dificuldades e começa a ter sucesso em alguma atividade proposta, isso pode atenuar suas frustações pelas dificuldades anteriormente vivenciadas e estimulá-lo a buscar outras superações, assim, vai se desenvolvendo pouco a pouco uma nova forma de se relacionar com a Ciência (FARIA; TORTELLA, 2015).

Geralmente, os programas escolares possuem grandes quantidades de temas de Química, com muitos detalhes, às vezes até desnecessários. Seu conteúdo é então passado priorizando a riqueza de detalhes, sem que haja qualquer preocupação com aquilo que o aluno já sabe ou com a relação que há entre a Química e o sujeito que aprende. O professor, ao correr com a matéria, dificulta a assimilação, favorecendo apenas a memorização, o que poderá levar o aluno apenas conseguir notas para aprovação. Inserido nesse ciclo, com aulas centradas apenas no ensino e no conteúdo, torna-se difícil que o aluno entenda e goste da Química.

É bastante comum ouvir relatos por parte dos estudantes de Química Geral e Inorgânica I que essa Ciência é de difícil compreensão, abstrata, profunda, sendo pouco comum se ouvir dizerem que não gostam de Química. Observa-se afinidade e dificuldade em sua aprendizagem.

Em relação ao suporte dado pela monitoria para esclarecer dúvidas ou até suprir lacunas inerentes aos assuntos abordados no Ensino Médio, 92\% dos entrevistados acreditam que o trabalho da monitoria atendeu às suas necessidades e $8 \%$ optaram por não responder (Figura 4). 
Figura 4 - Satisfação com o auxílio da monitoria para suprir conhecimentos prévios

Você acha que as aulas de monitoria Ihe ajudaram com esclarecimentos acerca dos assuntos que deveriam ter sidos trabalhados no ensino médio?

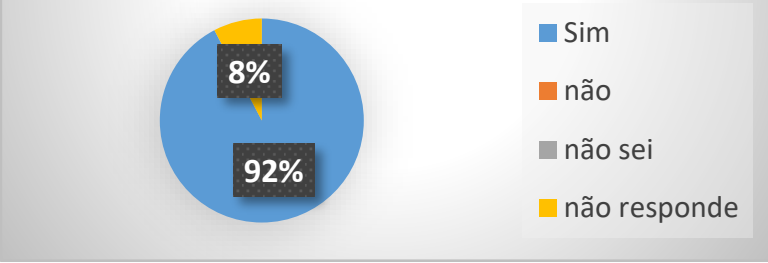

Fonte: elaborada pelas autoras.

Buscou-se saber também sobre o suporte dado pela monitoria sobre dúvidas em assuntos abordados pela disciplina Química Geral e Inorgânica I. Todos os entrevistados responderam sim, que houve um maior esclarecimento dos assuntos abordados em aula (Figura 5). Dessa forma, verificamos que as aulas de reforço de monitoria cumpriram seu papel, ou seja, funcionaram como uma atividade facilitadora da aprendizagem.

Figura 5 - Satisfação com a ajuda das aulas de monitoria

Você acha que a aula de monitoria Ihe deu esclarecimentos acerca dos assuntos trabalhados na disciplina Química Ge.\$inæ...

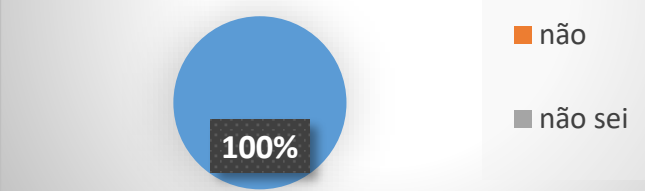

Fonte: elaborada pelas autoras.

O ensinar e o aprender são permeados por dimensões históricas e culturais, que conduzem os sujeitos, interferindo em suas relações. Ainda é possível perceber em alguns ambientes a existência de uma visão do professor do ensino superior como o detentor do saber, uma figura pouco aberta ao diálogo, conteudista e sem interesse em estabelecer certo grau de afetividade com seus alunos (QUADROS et al., 2010).

Sendo assim, a figura do monitor, alguém mais próximo e capaz de estabelecer uma relação horizontal com os alunos, pode funcionar como intermediário na relação interpessoal docente-discente. Outro fator a se analisar é que é possível que os estudantes se sintam mais à vontade para esclarecer dúvidas com o monitor, pois alguns se sentem constrangidos (embora não devessem) para fazer perguntas ao professor. O monitor pode oferecer suporte aos estudantes, auxiliando-os em suas dúvidas, facilitando o entendimento e contribuindo para melhoria de seu desempenho (RODRIGUES; SANTIAGO; REZENDE, 2017).

\footnotetext{
A sala de aula é um espaço de formação humana, de vivência e convivência e de relações pedagógicas que se destinam ao crescimento individual dos sujeitos na interação com o outro e com o conhecimento. É um espaço constituído pela diversidade e heterogeneidade de ideias, valores e crenças (QUADROS et al., 2010, p. 104).
}

No espaço das aulas de reforço, além da explanação de assuntos para esclarecimento de dúvidas e da resolução de exercícios, dentro do modelo tradicional, há também a possibilidade do uso de jogos, da realização de experimentos com materiais do cotidiano, da representação teatral, da montagem de modelos de moléculas a partir de massa de modelar ou de balões de aniversário, da realização de um trabalho mais voltado para o lúdico e para associações com o cotidiano. $\mathrm{O}$ fato de agora serem estudantes do ensino superior e de estarem se preparando para uma futura profissão não muda o fato de que continuam sendo aprendizes e que a motivação para estudar, e para aprender, pode ser estimulada de várias maneiras.

Ao serem questionados acerca de seu desempenho na disciplina e a relação deste com as contribuições da monitoria, $85 \%$ dos alunos entrevistados disseram que o seu desempenho não seria o mesmo se não tivessem contado com a monitoria e $15 \%$ não souberam responder (Figura 6). 
Figura 6 - Contribuição da monitoria para o desempenho dos alunos

Você acha que se não houvesse as aulas de monitoria o seu desempenho seria o mesmo?

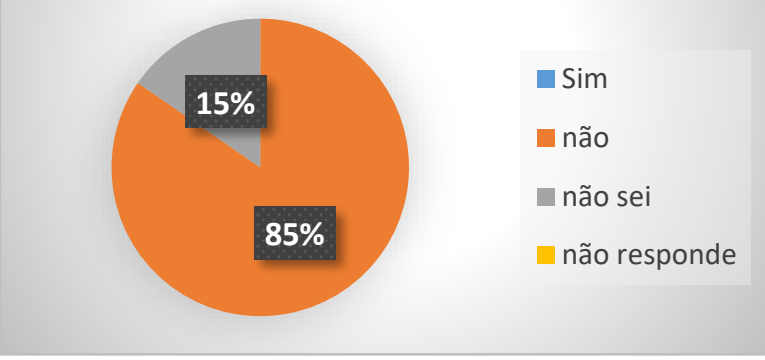

Fonte: elaborada pelas autoras.

Segundo Martins (2011, p. 45), “[...] a aprendizagem fornece elementos para que o indivíduo crie sua autonomia e busque, por conta própria, o conhecimento", pois a aprendizagem também "se dá no momento em que ocorre o conflito, a perturbação, o questionamento, gerando incomodo e a busca pelo conhecimento". É importante que o estudante esteja interessado em superar suas dificuldades para aprender. As aulas de reforço são voluntárias e participar delas é uma decisão que cada estudante deve tomar.

Para ter uma boa fluência em aulas de monitoria e para que as dúvidas apresentadas pelos alunos possam ser sanadas, é necessário que os monitores estejam preparados e tenham domínio sobre vários assuntos, não só de Química. A discussão em sala pode requerer conhecimentos que não são abordados pela disciplina, mas que facilitam sua compreensão.

A orientação do professor coordenador do projeto, o acompanhamento dos trabalhos, as reuniões de orientação também são importantes, pois o monitor ainda é um graduando e tem suas dúvidas. Neste sentido, buscou-se saber a opinião dos alunos acerca dos conhecimentos demonstrados pelo monitor. 92 $\%$ dos entrevistados disseram que os monitores estavam preparados para lhes atender e $8 \%$ não souberam responder (Figura 7).
Figura 7 - Opinião dos estudantes sobre a performance do monitor

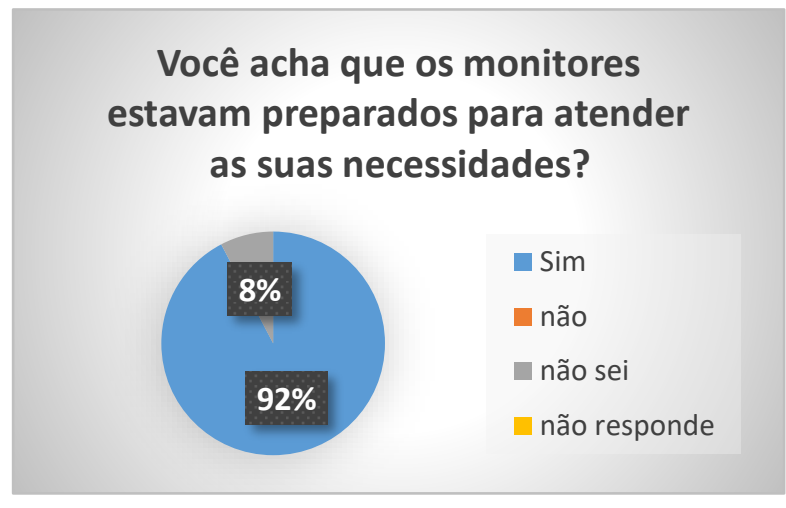

Fonte: elaborada pelas autoras.

Buscou-se saber também como os alunos monitorados percebiam o nível de conhecimento dos monitores. $77 \%$ responderam que estavam bem preparados e $23 \%$ razoavelmente preparados (Figura 8 ).

Pediu-se aos estudantes, via questão aberta, que sugerissem melhorias que agregassem mais qualidade ao trabalho da monitoria. Apenas $23 \%$ dos alunos deram alguma sugestão. Dentre elas estão: a possibilidade de tirar dúvidas de forma particular, atendimento individualizado; ocorrência das aulas de monitoria em mais de um dia na semana, maior tempo para discussão dos conteúdos; e ampliação do número de ferramentas pedagógicas facilitadoras da aprendizagem.

Figura 8 - Percepção dos estudantes quanto ao nível de preparo dos monitores

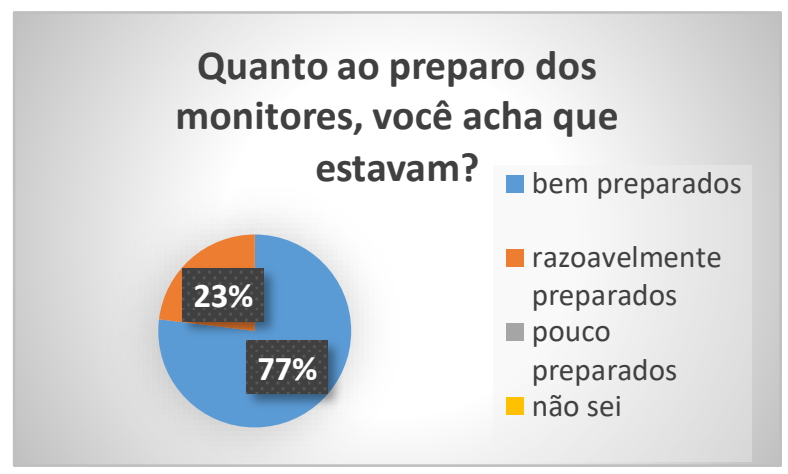

Fonte: elaborada pelas autoras.

Durante o semestre em questão foi realizado um experimento na aula de reforço para abordar estequiometria das reações com material do cotidiano. Foram feitos alguns 
modelos para facilitar o entendimento das moléculas e das ligações, usando massa de biscuit. Além disso, foi usado também um jogo para trabalhar número de oxidação. As analogias também são utilizadas para auxiliar no "processo de abstração e (re)construção conceitual, surgindo como uma alternativa de ação na compreensão de conceitos científicos" (SANTANA et al., 2017, p. 2).

Outra questão aberta buscou identificar as dificuldades percebidas pelos alunos relativas à disciplina. Destas foram citadas: o número de assuntos abordados e a dificuldade para assimilar todos eles; as lacunas existentes no conhecimento químico prévio, para montar as reações e para realização dos cálculos envolvendo estequiometria; a impossibilidade de participar das aulas de monitoria, porque elas são realizadas com base no horário dos calouros, os quais nem sempre coincidem com o horário dos repetentes; a dificuldade de assimilar assuntos como ligações primárias e secundárias usando a teoria da ligação de valência e não mais a teoria eletrônica de valência; conteúdo novo e mais elaborado, que não é abordado no ensino médio; a necessidade de aprender a linguagem química, cujo uso é necessário no ensino superior; dificuldades para assimilar os detalhes dos conteúdos abordados pela primeira vez, o que é um pouco do que foi dito anteriormente sobre ligações e suas teorias; a dificuldade de passar para o papel o que foi aprendido, ou seja, transcrição das ideias.

Parte das dificuldades supracitadas pode ser solucionada ampliando-se o número de horas e de dias para as aulas de revisão. Em um semestre anterior foram disponibilizados dois horários de monitoria, entretanto, o monitor do horário alternativo, cujo objetivo era atender aos repetentes, comparecia e os alunos não apareciam. Tudo depende da dinâmica da turma, de seu interesse e comprometimento.

Em relação ao rendimento geral na disciplina, $8 \%$ dos entrevistados acreditam que apresentaram bom rendimento, $50 \%$ rendimento médio e $42 \%$ rendimento ruim, mas todos acreditam que a monitoria foi muito importante para sua aprendizagem, como pode ser visto nas Figuras 9 e 10.
Figura 9 - Rendimento dos alunos na disciplina

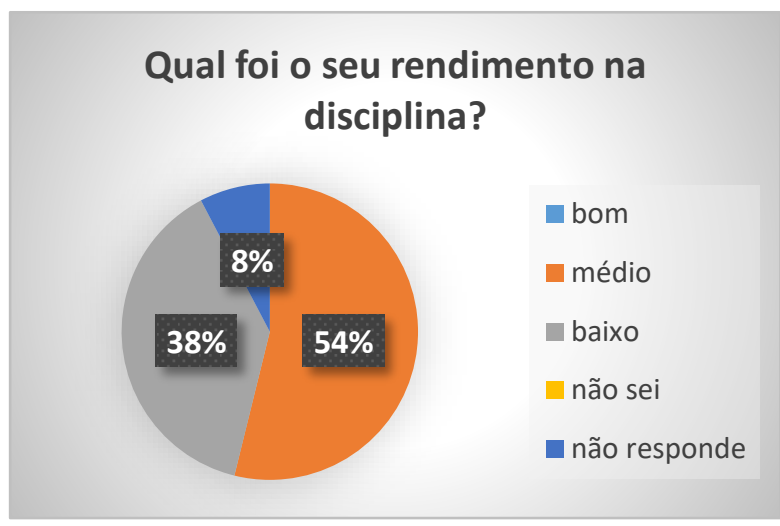

Fonte: elaborada pelas autoras.

Figura 10 - Importância da Monitoria para a disciplina

\section{Você acredita que a monitoria é importante para a disciplina?}

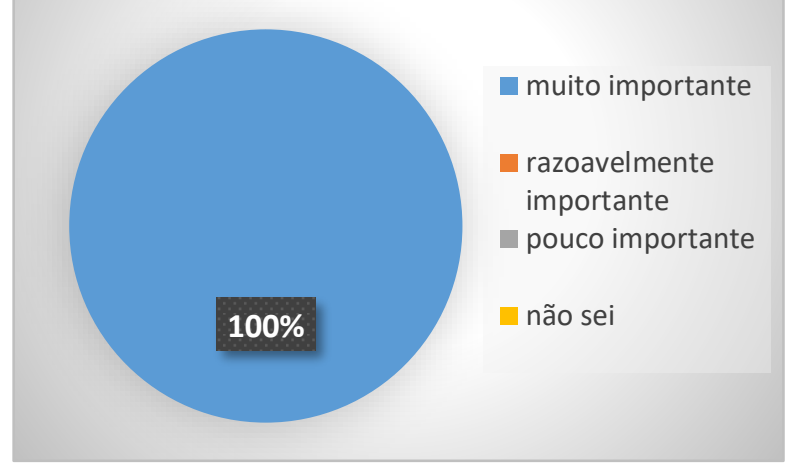

Fonte: elaborada pelas autoras.

Uma pergunta aberta buscou identificar as sugestões para melhorar o aprendizado. Foram citadas: a sugestão de que as aulas de Química tenham nível equivalente ao do Ensino Médio; maior número de ferramentas didáticas; uso do vocabulário do dia a dia, para que pessoas com dificuldade com a linguagem química possam entender o assunto; maior tempo e quantidade de aulas de monitoria (apenas uma aula por semana de duas horas); repetição das aulas práticas (aulas experimentais no laboratório didático), já que esse tipo de aula também auxilia muito o entendimento.

Em relação às sugestões citadas podemos afirmar que somente em aulas de monitoria é possível usar o mesmo formato de ensino do segundo grau; uso de jogos, experimentos com material do cotidiano, substituição de listas de exercícios por palavras cruzadas ou caçapalavras, montagem de estruturas químicas 
com balões e com massa de modelar ou de biscuit são estratégias usadas na monitoria, cuja tendência é se manter e/ou ampliar; a utilização de termos cotidianos e de analogias já vem sendo trabalhada. Porém, não é possível ministrar a disciplina usando apenas termos do dia a dia, é necessário que haja a inserção de novos termos técnicos, pois faz parte da competência da disciplina e da formação de futuros profissionais. Oferecer maior número de aulas de monitoria é algo a ser pensado e implementado a cada semestre, pois depende diretamente do perfil de cada turma, de sua necessidade e do interesse demonstrado. A repetição das aulas de laboratório é algo impossível, devido ao fato de os laboratórios didáticos estarem sem disponibilidade para uso em outros horários devido às necessidades também das outras disciplinas.

\section{CONSIDERAÇÕES FINAIS}

A monitoria é uma atividade de grande importância para vida acadêmica e a pesquisa realizada permitiu visualizar as melhorias no processo de aprendizagem dos alunos obtidas pelo trabalho realizado durante o primeiro semestre letivo de 2018 na UEFS.

Entretanto, é importante ressalvar a valiosa contribuição dada pelo grupo de estudantes monitorados para obtenção dos resultados obtidos, com sua participação e interesse pelas aulas no horário alternativo, aula de reforço ministrada pela monitora bolsista do projeto, auxiliada, algumas vezes, por monitores voluntários - e com o esclarecimento de dúvidas via WhatsApp ou pelo grupo de e-mail. De forma associada a isso, foi importante também poder contar com as contribuições dos alunos através das respostas dadas ao questionário, pois auxiliam na identificação das dificuldades vivenciadas pelos estudantes, para que estas sejam mais bem trabalhadas em semestres posteriores, bem como a oferta de sugestões para contribuir com melhorias que possam ser implementadas.

Os aspectos trabalhados na pesquisa versaram sobre as dificuldades de aprendizagem enfrentadas pelos discentes da disciplina Química Geral e Inorgânica I e as contribuições dadas pela atividade de monitoria durante o semestre 2018.1. A origem dessas dificuldades está relacionada com diversos fatores, que dependem de aspectos múltiplos e variam de sujeito para sujeito. A sala de aula é um espaço de convivência e de vivência, compartilhada por sujeitos heterogêneos, na qual acontece o ensinar e o aprender e na qual cada um tem seu ritmo de aprendizagem, que é influenciado por sua história, sua cultura, seu ambiente social, seu eu.

Os resultados da pesquisa mostraram que a monitoria pode oferecer contribuições e intervir no processo de forma positiva, mas isso depende diretamente do interesse do estudante para superar suas dificuldades em Química e para enfrentar o novo.

O novo amedronta e as pessoas nem sempre se relacionam bem com as mudanças. Estudar Química nos moldes do Ensino Superior requer do aprendiz uma adaptação ao novo, e Química Geral e Inorgânica I faz parte desse processo de adaptação ao Ensino Superior. Aceitar esse desafio e enfrentá-lo faz parte do trabalho de transformar essa novidade em algo conhecido e, aos poucos, dominado. Segundo Freire (1996), o novo não pode ser aceito só porque é novo, também não pode ser negado pela mesma razão, faz parte do pensar certo expor-se ao risco. Isso gera crescimento pessoal.

\section{REFERÊNCIAS}

ALBUQUERQUE, M. A. C. et al. Bioquímica como Sinônimo de Ensino, Pesquisa e Extensão: um Relato de Experiência. Revista Brasileira de Educação Médica, v. 36, n. 1, p. 137-142, 2012.

AMORIM, T. B.; PAIXÃO, M. F. M.; SILVA, A. G. C. A importância da monitoria para o aprendizado de Química. Revista de Ensino de Engenharia, v. 36, n. 2, p. 27-34, 2017.

BARRETO, A. L.; FILGUEIRAS, C. A. L. Origem da universidade brasileira. Química Nova, v. 30, n. 7, p. 1780-1790, 2007.

BRASIL. Senado Federal, Lei Federal $\mathbf{n}^{\circ}{ }^{5540}$, de 28 de novembro de 1968. Disponível em: http://www2.camara.leg.br/legin/fed/lei/1960- 
1969/lei-5540-28-novembro-1968-359201normaatualizada-pl.pdf. Acesso em: 21 jan. 2018.

DIAS, A. M. I. A monitoria como elemento de iniciação à docência: ideias para uma reflexão. In: SANTOS, M. M.; LINS, N. M. L. (Orgs.). A monitoria como espaço de iniciação à docência: possibilidades e trajetórias. Natal, RN: EDUFRN: Editora da UFRN, 2007.

FARIA, A.P.; TORTELLA, J.C. Afetividade e dificuldades de aprendizagem: compreendendo conceitos e sua inter-relação no dia a dia da sala de aula. Cadernos da Pedagogia, São Carlos, v. 8, n. 16, p. 15-27, jan-jun 2015.

FREIRE, P. Pedagogia da autonomia: saberes necessários à prática educativa. São Paulo: $\mathrm{Paz}$ e Terra, 1996.

LINS, L. F. et al. A importância da monitoria na formação acadêmica do monitor. 2009. Disponível em: http://www.eventosufrpe.com.br/jepex2009/c d/resumos/r0147-1.pdf. Acesso em: 11 jan. 2018.

MARTINELLI, S. C.; SISTO, F. F. Inter-relação de conteúdos na construção do conhecimento por conflito cognitivo. Psicologia em Estudo, Maringá, v. 6, n. 2, p. 81-87, jul./dez. 2001.

MARTINS, E. de S. Aprendizagem: representações sociais de estudantes concluintes de cursos de licenciatura. In: RIBEIRO, M. L.; MARTINS, E. de S.; CRUZ, A. R. S. da (Orgs.). Docência no ensino superior: desafios da prática Educativa. Salvador, EDUFBA, 2011.

MOLINA, O. A escola e o ato de ensinar. Faculdade de educação. São Paulo, jan.-dez, 1985.

OLIVEIRA, H. P.; PASSOS, W. A. C. Ensino da Física Básica para as Engenharias: o caso da UNIVASF. Revista de Ensino de Engenharia v. 33, p. 9-14, 2014.

PESSOA, W. R; ALVES, J. M. Motivação para estudar química: configurações subjetivas de uma estudante do segundo ano do ensino médio. Anais... Encontro Nacional de Pesquisa em Educação Em Ciências, 8, 2011, Campinas. Campinas, 2011. Disponível em: http://www.nutes.ufrj.br/abrapec/viiienpec/res umos/R0164-1.pdf. Acesso em: 17 abr. 2020.

QUADROS, A. L. de. et al. A percepção de professores e estudantes sobre a sala de aula de ensino superior: expectativas e construção de relações no curso de Química da UFMG. Ciência \& Educação, v. 16, n. 1, p.103-114, 2010.

ROCHA, J. S.; VASCONCELOS, T. C. Dificuldades de aprendizagem no ensino de Química: algumas reflexões. Anais... Encontro Nacional de Ensino de Química (XVIII ENEC), 2016, n.p. Florianópolis, 2016. Disponível em: http://www.eneq2016.ufsc.br/anais/resumos/R 0145-2.pdf. Acesso em: 27 mai. 2019.

RODRIGUES, O. R. da S.; SANTIAGO, J. S.; REZENDE, I. C. C. Monitoria e o processo de aprendizagem do aluno: um estudo da turma de contabilidade II. Mangaio Acadêmico, v. 2, n. 3, p.1-11, jul/dez, 2017.

SANTANA, I. C. H. et al. Analogias, concepções e uso na sala de aula: um estudo de caso acerca do tema. Anais... XI Encontro Nacional de Pesquisa em Educação em Ciências (XI ENPEC), 2107, p. 1-7, Florianópolis, 2017. Disponível em: http://www.abrapecnet.org.br/enpec/xienpec/anais/resumos/R1967-1.pdf. Acesso em: 28 mai. 2019.

SILVEIRA, E.; SALES, F. de. A importância do Programa de Monitoria no ensino de Biblioteconomia da Universidade do Estado de Santa Catarina (UDESC). Inf. e Doc., Ribeirão Preto, v. 7, n. 1, p. 131-149, 2016. 


\section{DADOS BIOGRÁFICOS DOS AUTORES}

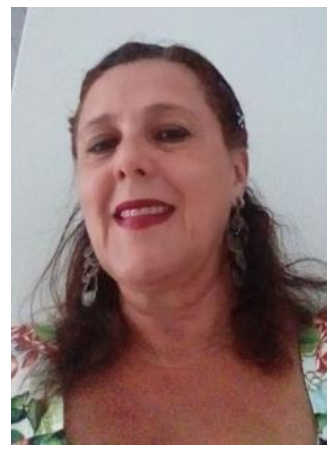

Maria de Fátima Mendes Paixão - Graduação em Engenharia Química, Universidade Federal da Bahia, 1979. Graduação em Educação Física, Universidade Católica do Salvador, 1989. Mestrado em Engenharia Química, Universidade Federal da Bahia, 1995. Doutorado em Desenvolvimento Sustentável, obtido pela Universidad de Salamanca e reconhecido pela Universidade de Brasília, 2006. Especialização em Ensino de Química e Biologia, 2016, Universidade do Vale do São Francisco. Departamento de Ciências Exatas da Universidade Estadual de Feira de Santana (DEXA/UEFS). Foi uma das coordenadoras do Programa de Iniciação à Docência do subprojeto de Química, do PIBID/QUÍMICA/UEFS, no período 2014/2018, realiza pesquisa na área de Educação Química em busca de metodologias alternativas para o ensino de Química, com vistas a contribuir para melhorias da aprendizagem dessa ciência. Nesse sentido, orienta estudantes de Licenciatura em Química da UEFS que realizam seu Trabalho de Conclusão de Curso realizando sua pesquisa na já citada área e estudantes do projeto de monitoria de Química para o curso de Engenharia de Alimentos na realização de pesquisas que contribuam para melhoria da aprendizagem de Química.

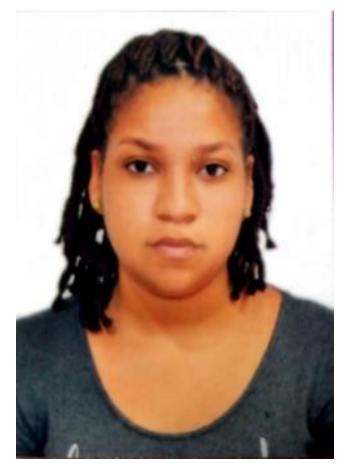

Elaine Santos Silva - Monitoria da disciplina EXA 409: Química Geral e Inorgânica I, 28 de agosto de 2017 a 27 de agosto de 2018 - Universidade Estadual de Feira de Santana. Título do Projeto: Desenvolvimento de tecnologia para processamento de frutas cultivadas no semi-árido baiano. Título da Pesquisa: Clarificação do licor de jamelão. 01 de dezembro de 2018 a 01 de agosto de 2019 - Universidade Estadual de Feira de Santana.

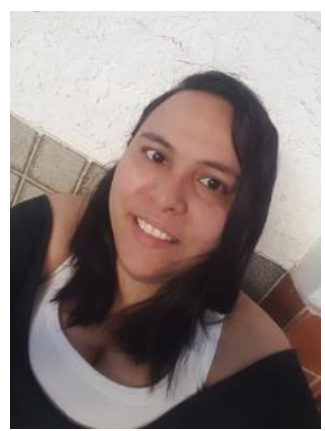

Emilly Adorno de Lima Vasconcelos - Graduação em Administração pela Escola de Negócios do Estado da Bahia (2009). Pós-graduação em Especialização em Gestão Estratégica de Negócios pela Fundação Visconde de Cairu (2011). Graduanda em Engenharia de Alimentos pela Universidade Estadual de Feira de Santana. Projeto de Extensão: Implementação de Rede de Pesquisa e Extensão para Estudos Interdisciplinares em Antocianinas: Potencialidades de Fontes Naturais do Estado da Bahia em Educação e Saúde, Resolução CONSEPE 050/2014 (2014 a 2016). Monitoria voluntaria da disciplina EXA 409: Química Geral e Inorgânica I (2014 a 2018). 